\title{
COST EFFECTIVENESS ANALYSIS OF THE TOTAL HIP REPLACEMENT THERAPY FOR HIP OSTEOARTHRITIS: A SYSTEMATIC REVIEW
}

\author{
Nining Tri Maryani, Mardiyati Nadjib, Pamudji Utomo \\ Faculty of Public Health, Universitas Indonesia
}

\begin{abstract}
Background: Hip osteoarthritis is inflammation of the joint caused by deterioration of the articular cartilage that protects the end of the joint. Total hip replacement (THR) surgery has been considered as the most effective treatment for osteoarthritis. However, studies into the cost effectiveness of THR are lacking. This study aimed to systematically review the cost effectiveness analysis of the total hip replacement therapy for hip osteoarthritis.

Subjects and Method: A systematic review was conducted through PubMed database. The inclusion criteria were articles published in English-language and around last 5 years. The keywords were "cost effectiveness analysis", "total hip replacement", "hip osteoarthritis", and "treatment". The articles selection were using filtering. The qualitative thematic analysis was used for synthesis.

Results: Nine of 518 articles were identified for final review. THR surgery was more cost-effective for osteoarthritis than without surgery. This cost-effectiveness was influenced by age, Body Mass Index (BMI), THR procedure, duration of rehabilitation, type and brand of THR implant.

Conclusion: THR surgery is more cost-effective than without THR surgery for hip osteoarthritis.
\end{abstract}

Keywords: hip osteoarthritis, total hip replacement, cost effectiveness analysis.

\section{Correspondence:}

Nining Tri Maryani. Faculty of Public Health, Universitas Indonesia, Depok, West Java, Indonesia. Email: ni2ngtm@gmail.com. Mobile: 082138233382.

\section{BACKGROUND}

Osteoarthritis (OA) is the most common form of joint disease, and results from progressive degenerative changes in joint structure. Pelvic osteoarthritis is a progressive joint disease in the hip joint, typically occurring in middle-aged to elderly patients. This disease occurs when joint cartilage is damaged due to mechanical pressure or biochemical changes. Symptoms of pelvic osteoarthritis include joint pain and stiffness, swollen joints, sound when the joints move, and decreased joint function (American College Rheumatology, 2012).

The prevalence of total osteoarthritis in Indonesia was 34.3 million in 2002 and reached 36.5 million in 2007. It is estimated that $40 \%$ of the population above 70 years old suffer from osteoarthritis, and $80 \%$ of osteoarthritis patients have limited mobility in various degrees from mild to severe which results in reducing quality of life due to a fairly high prevalence. Because of its chronicprogressive nature, osteoarthritis has a large socio-economic impact, both in developed and developing countries. An estimated 1 to 2 million elderly people in Indonesia suffer from disabilities due to osteoarthritis (Soeroso, 2006).

Treatment of pelvic osteoarthritis is divided into four ways, namely lifestyle changes, no pharmacological therapy, pharmacological therapy, and surgery (Vincent and Watt, 2014). Surgery for pelvic Osteoarthritis requires a large fee. Direct costs incurred by osteoarthritis include visits to the doctor, medication, and surgery. Indirect costs include all that is lost due to inability to work. The costs associated with osteoarthritis can be a significant value in the elderly who 
become unable to carry out daily activities and thus require the help of others (Royal College of Physicians, 2008). The prevalence of OA increases with age, and with a constant increase in the global aging population (United Nations Department of Economic and Social Affairs, 2013).

Osteoarthritis causes pressure on scarce resources. For example, in a recent study, the total annual direct cost of osteoarthritis in the US was estimated to be double that of similar patients who did not have osteoarthritis (Le et al., 2012).

In the UK, the total cost of treating osteoarthritis is estimated at more than $£ 1$ billion (2010 prices) (Chen et al., 2009). National survey data, estimates an increase in insurance companies spending for women in the US with osteoarthritis to USD4,833 for men with osteoarthritis, an additional insurance fee estimated at USD4,036. Therefore a cost-effective approach to the management of osteoarthritis is needed.

Total Pelvic Replacement Surgery also includes surgery that is not small (high cost) so the need for an analysis of the effectiveness of treatment and management of osteoarthritis involves a multidisciplinary approach and various management options including patient education and management, non-pharmacological care and pharmacological care. The clinical guidelines were recently updated for the management of OA, issued by the National Institute for Health.

Superior Care (NICE), comprehensive and integrated care involving health professi- onal, patient, and career is among the key recommendations intended to ensure maximum benefit for patients. Apart from these pharmacological and non-pharmacological interventions, there are also surgical interventions that are more expensive and are usually limited to patients who do not respond to other forms of treatment. Due to an increase in the number of parents, there has been an increase in demand for surgical interventions such as joint arthroplasty which has led to an increase in costs associated with osteoarthritis.

Total hip replacement surgery (THR) is considered one of the most effective treatments for osteoarthritis but the cost of THR surgery in patients with hip osteoarthritis. This study aims to analyze the cost effectiveness in cases of osteoarthritis who perform THR surgery.

\section{SUCJECTS AND METHOD}

\section{Study Design}

A systematic review was carried out from PubMed. The keywords used are Cost Effectiveness Analysis, Total Hip Replacement, hip osteoarthritis, treatment (Table 1).

This study aimed to review published economic evaluations aimed at assessing and summarizing evidence about the cost effectiveness of THR surgery for pelvic osteoarthritis therapy. This systematic review follows the PRISMA guidelines (PRISMA checklist). An initial literature search was conducted in 5 years starting in January 2015 to January 2019. 

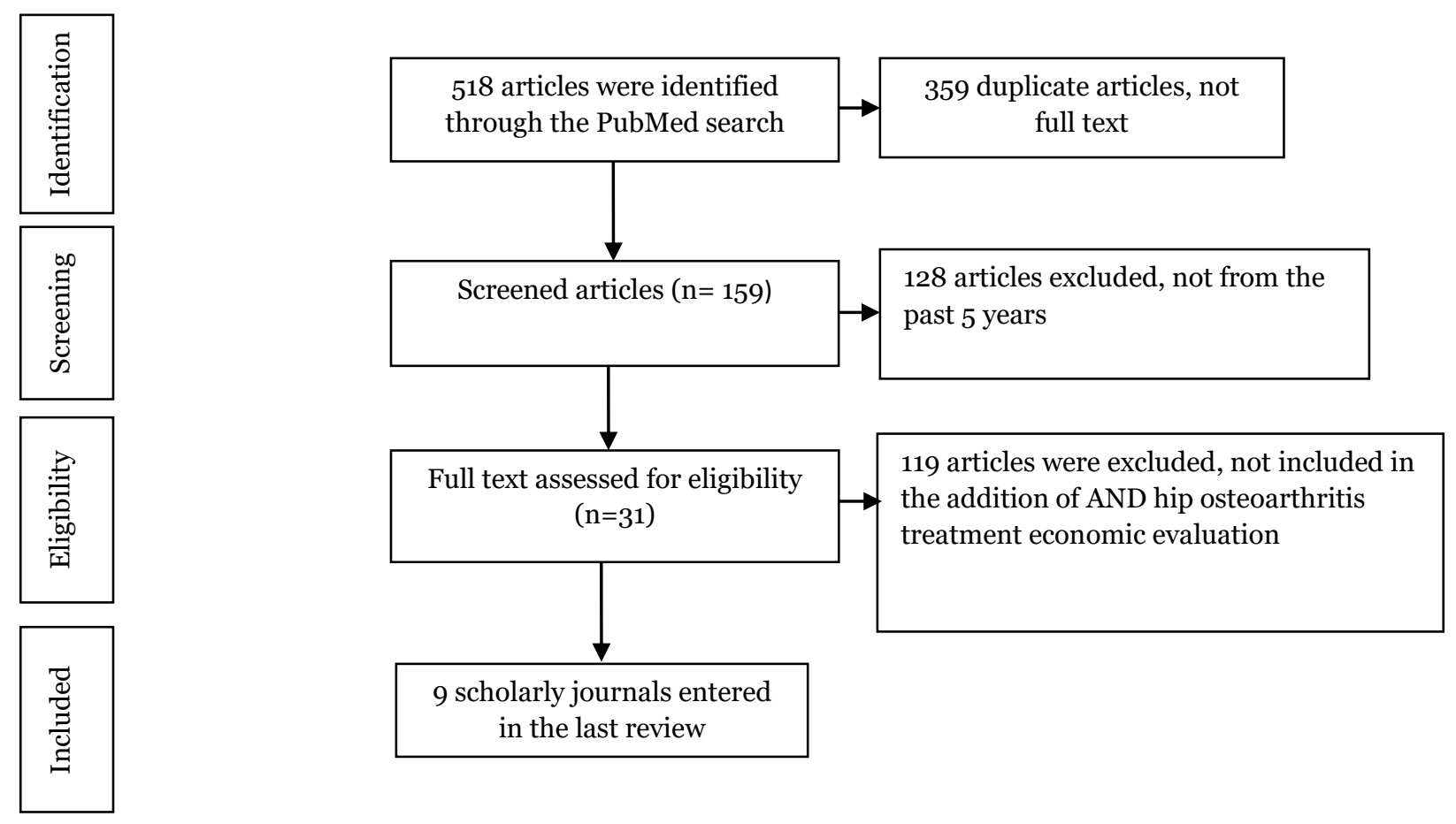

Figure 1. PRISMA Flow Diagram

\section{Study Variables}

The dependent variable in this study is hip osteoarthritis. The independent variable is cost effectiveness.

\section{Inclusion and exclusion criteria}

The inclusion criteria in this study were to use a population of patients with pelvic osteoarthritis, have a history of Total Hip Replacement (arthroplasty) surgery, journal articles published in the last 5 years (January 2015 to January 2019), use English and full text, and the results of research are economic evaluation.

Meanwhile, the exclusion criteria used are the population has a history of knee osteoarthritis, rheumatoid arthritis, lupus arthritis, ankylosing spondylitis, conservative intervention, total knee replacement, articles published before January 2015 and after
January 2019, use languages other than English and non-full text, as well as non-economic evaluation results. The analysis was carried out by applying a thematic analysis approach to synthesize review findings based on systematic reviews.

\section{RESULTS}

Database search yielded 518 articles after removing duplicates and displaying full text, with 159 articles meeting scientific journal criteria, the last 5 years (January 2015 January 2019, full text. 31 articles fulfilling Journal criteria, the last 5 years (January 2015 to January 2019) 9 articles were identified for the final review with full text, the last 5 years, hospital and Pelvic Osteoarthritis economic evaluations.9 papers for final qualitative synthesis were finally included. 
Table 2. The paper carried out the final qualitative synthesis

\begin{tabular}{|c|c|c|c|c|}
\hline Author & Year & Place & Method & Result \\
\hline Kunkel et al. & 2018 & $\begin{array}{l}\text { Lebanon, } \\
\text { New } \\
\text { hapsire }\end{array}$ & $\begin{array}{l}\text { Markov } \\
\text { and QALY } \\
\text { methods }\end{array}$ & $\begin{array}{l}\text { THR is a cost-effective choice compared to non- } \\
\text { operative management in patient's } \geq 80 \text { years } \\
\text { old. This analysis can inform policy regarding } \\
\text { THA in elderly patients (Kunkel ST et al, 2018). }\end{array}$ \\
\hline Seeber et al. & 2017 & $\begin{array}{l}\text { German } \\
\text { and } \\
\text { Netherland }\end{array}$ & $\begin{array}{l}\text { Study } \\
\text { prospective } \\
\text { controlled } \\
\text { observation } \\
\text { al }\end{array}$ & $\begin{array}{l}\text { The long-term economic aspects in both coun- } \\
\text { tries, Germany and the Netherlands, related to } \\
\text { time reduction factors for post-operative medical } \\
\text { rehabilitation of hip joint replacement are asses- } \\
\text { sed from a community perspective, to get a first } \\
\text { impression of cutting costs for rehabilitation, as } \\
\text { practiced in the Netherlands, resulting in an } \\
\text { efficient health care system compared to those in } \\
\text { the Netherlands. Germany which cuts medical } \\
\text { rehabilitation time. This study is a prospective } \\
\text { study with a questionnaire (Seeber et al., 2017). }\end{array}$ \\
\hline
\end{tabular}

$\begin{array}{llll}\text { Koenig et al. } 2016 & \begin{array}{l}\text { Lebanon, } \\ \text { New } \\ \text { Hampshire }\end{array} & \begin{array}{l}\text { Markov } \\ \text { method }\end{array}\end{array}$

Jamesson et 2015 al.

United Kingdom

Cohort retrospecti ve method

Ponnusamy 2018 et al.

$\begin{array}{ll}\text { Ontario, } & \text { Markov } \\ \text { London, } & \text { method } \\ \text { Canada } & \end{array}$

Pennigton et 2015 al.

London, Markov UK method
Compared with the non-surgical care of patients with THR surgery the average annual productivity of patients increased by USD 9503 (95\% CI= USD 1,446 - USD 17,812). The THR increased the average direct lifetime cost of USD 30,365 which was offset by a lifetime savings of USD 63,314 from increased productivity (Koening et al., 2016).

Hip joint replacement surgery (THR) with cement fixation, using standard sized polyethylene cups and heads offers good results, with the lowest risk and lowest cost. The most commonly used implants without cement and overlay are associated with higher and more expensive revision risks, while perceptions of improved function and longevity are not supported (Jamesson et al., 2015)

Pelvic joint replacement surgery in which BMI patients show cost-effectiveness of treatment, Over a 15-year period, ICER for THA vs. NM is as follows: normal weight (USD 6,043/QALYs [adjusted quality of life]], overweight (USD 5,770/QALYs), obesity (USD 5425/QALYs), very obese (USD 7,382/QALYs), unnatural obesity (USD 8,338/QALYs), and super obesity (USD 16,651/QALYs) The 2 highest BMI groups have additional QALY and higher incremental probabilistic sensitivity analysis shows that THA will be cost effective in $100 \%$ of normal simulation, overweight, obesity, severe obesity, and unnatural obesity, and $99.95 \%$ simulated super obesity on the ICER threshold of USD50,000/ QALYs. (Ponnusany et al., 2018)

In THR surgery with samples of women with osteoarthritis aged 70 years, Exeter V40 Elite 


$\begin{array}{cclc}\text { Carnes et al. } 2016 & \begin{array}{l}\text { North } \\ \text { Carolna, } \\ \text { USA }\end{array} & \begin{array}{l}\text { Markov } \\ \text { method }\end{array} \\ \end{array}$

Rykov et al. $2016 \quad$ Netherland

Observatio nal control method (POLADA -trial)

$\begin{array}{ccll}\text { Martin et al. 2016 } & \begin{array}{l}\text { London, } \\ \text { Ontario- } \\ \text { Canada }\end{array} & \begin{array}{l}\text { Observatio } \\ \text { nal control } \\ \text { method }\end{array}\end{array}$

Plus Ogee had the lowest revision risk (5.9\% revision risk, 9.0 QALYs) and CPT Trilogy had the highest QALY (revised risk 10.9\%, 9 risk, 3 QALY). Compared with Corail Pinnacle (9.3\% revision risk, 9.22 QALYs), with the most commonly used brands.

However, it is unlikely that the cement brand is the most cost-effective. The same pattern of results was observed for men and other ages. The advantage in quality of life after total hip arthroplasty, rather than the risk of revision, is a major driver of cost effectiveness (Pennington MW et al. 2015)

The cost effectiveness of THR surgery with ceramic bone heads is highly dependent on the cost difference between the ceramic head and femoral metal heads and the age of the patient. With a cost difference of USD325, ceramic-topolyethylene pads are cost effective for patients aged $<85$ years. At a cost difference of USD600, it is cost-effective to utilize ceramic-to-polyethylene pads in patients $<65$ years old, and, at a differential of USD1,003, ceramic-to-polyethylene pads are not cost-effective at any age (Carnes KJ et al, 2016)

The cost effectiveness of THR surgery is assessed by obtaining data on medical costs inside and outside the hospital and other non-medical costs. The measurements were taken before surgery, two and six weeks, three months and one year postoperatively. There is some evidence that the THR surgery approach with the anterior surgery method results in a reduction in tissue damage and a faster recovery in the immediate postoperative period, compared to the poster lateral approach (Rykov et al., 2016).

In the THR operation with a study involving 24 patients, both groups had the same age (58.9 vs. 63.9 years), height (169.2 vs. $170.9 \mathrm{~cm})$, weight (80.2 vs. $78.6 \mathrm{~kg}$ ), BMI (27.9 vs. $26.3 \mathrm{~kg} / \mathrm{m}^{2}$ ), ASA score (2.2 vs. 2.2), and CCI score (2.3 vs. 2.9). The average cost per patient from a hospital perspective for a single stage group is USD10,728.13 ( $\mathrm{SD}=621.46)$ (Martin et al., 2016). The results show that a one-stage bilateral THA DAA results in significant cost savings compared to a two-stage THA DAA.

Based on the results of the review, it was found that there were 3 papers that used the Markov method in a cost-effectiveness analysis research in osteoarthritis patients undergoing hip joint replacement surgery with the results of the study showing that osteoarthritis patients with hip replacement surgery as therapy. Compared to nonsurgical care, a cost effectiveness analysis increases the patient's average annual productivity by USD 9,503 .

The THR increased the average direct lifetime cost of USD 30,365 offset by a life- 
time savings of USD 63,314 from increased productivity.

Ponnusamy et al. (2018) suggested that in patients who had joint replacement surgery with a patient's BMI value over a 15year period, ICER for THA vs. NM was as follows normal weight (USD6,043/QALYs (adjusted quality of life)), excess body weight (USD5770/QALYs), obesity (USD5425/QALYs), very obese (USD7382/QALYs), unnatural obesity (USD8338/QALYs), and super obesity (USD16,651/ QALYs). The 2 highest BMI groups have additional QALY and higher additional costs. Probabilistic sensitivity analysis shows that the THR will be cost effective in $100 \%$ of normal simulation, overweight, obesity, severe obesity, and unnatural obesity, and 99.95\% simulated super obesity at the ICER threshold of USD50,000/QALYs.

Carnes et al. (2016) found that the proportion of satisfaction of the cost effectiveness of ceramic heads is highly dependent on the difference in cost between the ceramic head and the femoral metal and the age of the patient. With a cost difference of USD325, ceramic-to-polyethylene pads are cost effecttive for patients aged $<85$ years. At a cost difference of USD6oo, it is costeffective to utilize ceramic-to-polyethylene pads in patients $<65$ years old, and, at a differential of USD1.003, ceramic pads on polyethylene are not cost-effective at any age.

From the results of the above review, also found 3 papers using prospective observational control methods, namely the Seeber et al. (2017) who found long-term economic aspects of patients about cutting costs of rehabilitation of postoperative hip replacement patients in the Netherlands and Germany were assessed from a community perspective get the first impression of cutting costs for rehabilitation, as practiced in the Netherlands, which results in an efficient health care system. Rykov et al. (2016) found that cost effectiveness was assessed by obtaining data on medical costs inside and outside the hospital and other non-medical costs.

Measurements were taken before surgery, two and six weeks, three months and one year postoperatively. There is some evidence that the anterior approach results in reduced tissue damage and faster recovery in the immediate postoperative period, compared to the poster lateral approach. Martin et al. also found 24 patients included in this study. Both groups had the same age (58.9 vs. 63.9 years), height (169.2 vs. $170.9 \mathrm{~cm}$ ), weight (80.2 vs. $78.6 \mathrm{~kg}$ ), BMI (27.9 vs. $26.3 \mathrm{~kg} / \mathrm{m}^{2}$ ), ASA score (2.2 vs. 2.2), and CCI score (2.3 vs. 2.9).

The average fee for each patient from the hospital perspective for one-stage bilateral is USD10,728.13 $(\mathrm{SD}=621.46)$ if it is compared, USD12,670.63 $(\mathrm{SD}=519.72)$ for second stage bilateral. (Mean= USD1,942.50; 95\%CI= USD1,457.49 until USD2,427.51; $\mathrm{p}=$ o.001). Similarly, from the perspective of health department, the fee for one-stage bilateral is USD $12,552.34(\mathrm{SD}=644.93)$ compared to USD14,740.58 (SD=598.07) for the second stage bilateral. (Mean= USD2,188.24; 95\%CI= USD1,661.67 until USD2,714.81; $\mathrm{p}=0.001)$. There were no significant differences in the rates of complications between groups. The largest percentage of total cost savings from a hospital perspective is related to operating room staff costs and OR arrangements (55\%). Our results show that a one-stage bilateral THA DAA results in significant cost savings compared to a two-stage THA DAA

As for the retrospective cohort, there is one article, namely research from Jamesson et al. (2015) who discovered cement fixation, using standard sized polyethylene cups and heads in joint replacement surgery offered good results, with the lowest risk and lowest cost. 
The most commonly used implants without cement and overlay are associated with a higher and more expensive risk of revision, while perceptions of improved function and longevity are not supported. And there are also 2 articles examining QALY, Pennigton et al. (2015), stated that for women with osteoarthritis aged 70 years, Exeter V40 Elite Plus Ogee has the lowest revision risk (5.9\% revision risk, 9.0 QALYs) and CPT trilogy has the highest QALY (10.9\% revised risk, 9.3 QALY risk). Compared to Corail Pinnacle (9.3\% revision risk).

\section{DISCUSSION}

This systematic review was carried out with the aim of assessing the cost effectiveness of hip osteoarthritis patients who received surgical intervention in the form of hip joint replacement surgery (THR).

Overall, the results of the review show that economic analyzes such as an analysis of the cost effectiveness of total surrogate surgeries in osteoarthritis patients are more effecttive when seen in the long term, especially in the quality of life of osteoarthritis patients than those who do not undergo surgery with different influential factors. The cost effecttiveness is influenced by among others the procedure or length of rehabilitation after surgery, the type and brand of implants in the THR, age, Basal Mass Index (BMI) and the THR procedure using the anterior method.

Factors that influence the results of cost effectiveness analysis in THR surgery patients from patient factors are the age factor and MBI value. Patients aged $>80$ years with advanced OA levels are more cost effective than patients $<80$ years old especially in the postoperative rehabilitation factors required. Patients with fair BMI values are more effective than those with excess BMI values, especially on the quality of life factor after undergoing surgery. As for the method factor, it was found that THR operations using the anterior method and using cement were more cost-effective than those using the poster lateral method because of less injury to the operation and a lower risk of repeat operation. In the machine factor, in patients with a type of ceramic hump implant is more effective in patients with advanced age $(>70$ years).

THR surgery is more cost effective than non-operative and is recommended for the treatment of severe pelvic Osteoarthritis patients. The weakness of this study is that it only uses one search method, PubMed. Another disadvantage is limited time. It is hoped that this research can support further research.

\section{REFERENCES}

American College Rheumatology. (2012). American of Rheumatology Guidelines for the treatment of Rheumatology Arthritis: 12

Carnes KJ et al. (2016). Cost analysis of ceramic heads in primary total hip arthroplasty, USA, 98(21): 17941800.

Chen A et al. (2012). The global economic cost of osteoarthritis: How UK compares. Arthritis; 2012: 698709.doi101155/2012/698709

Handayani PW (2017). Systematic Review using PRISMA (Preferred Reporting Items for Systematic Reviews and Meta-analyses). Workshoop Riset Sistem Informasi Fakultas Ilmu Komputer UI 2017:1-28. doi: 10.1177/1750635210360083

Jamesson SS et al. (2015) Implant optimization for primary hip replacement in patients over 60 years with osteoarthritis: a cohort study of clinical outcomes and implant costs using data from England and Wales, United Kingdom. PLoS One, 10(11): 
e0140309. doi: 10.1371/journal.pone.0140309.

Koenig L et al. (2016). Estimating the Societal Benefits of THA after Accounting for Work Status and Productivity: A Markov Model Approach, Lebanon. Clin Orthop Relat Res, 474(12): 2645-2654.

Kunkel ST et al. (2018). The cost Effectiveness of Total Hip Replacement in patients 80 years of age and older, Lebanon J Arthroplasty. 33(5): 1359-1367. doi: 10.1016/j.arth.2017.11.063.

Le TK et al. (2012). Health care costs in US patients with and without a diagnosis of osteoarthritis. J Pain Res. 2012: 5 23-30.

Pennigton MW et al. (2015). Lifetime cost effectiveness of different brands of prosthesis used for total hip arthroplasty, London UK. Bone Joint J. 97-B(6): 762-70. doi: 10.1302/o301620X.97B6.34806.

Ponnusamy KE et al. (2018). Cost Effectiveness of Total Hip Arthroplasty versus non-operative management in norma, overweight, obese, severely obese, morbidly obese and super obese patients: A markov model, London UK.
Rykov K et al. (2016). The design of a randomized controlled trial to evaluate the (cost) effective-ness of the poster lateral versus the direct anterior approach for total hip arthroplasty (POLADA-trial), Belanda. BMC Musculoskelet Disord. 17(1): 476.

Soerono et al. (2006). Osteoathritis. Buku Ajar Ilmu Penyakit Dalam jilid II edisi IX (Osteoarthritis. Internal Medicine teaching volume II edition IX). Jakarta: Fakultas Kedokteran UI, 2006: 1195-1201

Siswanto (2010). Systematic Review Sebagai Metode Penelitian untuk Mensintesis HasilHasil Penelitian (Sebuah Pengantar). Buletin Penelitian Sistem Kesehatan 2010, 13: 326-33

Seeber GH et al. (2017). Effectiveness of rehabilitation after a total hip arthroplasty: a protocol for an observational study for the comparison of usual care in the Netherlands versus Germany. BMJ Open. 2017 Aug 11; 7(8):e016020. doi: 10.1136/bmjope$\mathrm{n}-2017-016020$

Martin GR et al. (2016). A cost analysis of single-stage bilateral versus two stage direct anterior total hip arthroplasty, Canada. Hip Int. 26(1):15-9. doi: 10.5301/hipint.5000292. 